\title{
Diffusion-Limited Crystallization: A Rationale for the Thermal Stability of Non-Fullerene Solar Cells
}

\author{
Liyang Yu, ${ }^{* \dagger, \ddagger \odot ~ D e p i n g ~ Q i a n, " ~ S a r a ~ M a r i n a, ~}{ }^{\perp}$ Ferry A. A. Nugroho, ${ }^{\S}$ Anirudh Sharma, ${ }^{\#, \nabla_{\odot}}$
} Sandra Hultmark, Anna I. Hofmann, ${ }^{\ddagger}$ Renee Kroon, ${ }^{\ddagger}$ Johannes Benduhn, ${ }^{\triangleright}$ Detlef-M. Smilgies,

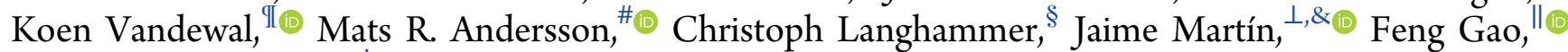
and Christian Müller**\$(1)

${ }^{\dagger}$ College of Chemistry, Sichuan University, Chengdu 610064, P. R. China

${ }^{\ddagger}$ Department of Chemistry and Chemical Engineering and ${ }^{\S}$ Department of Physics, Chalmers University of Technology, 41296 Göteborg, Sweden

"Department of Physics, Chemistry and Biology (IFM), Linköping University, SE-581 83 Linköping, Sweden

${ }^{\perp}$ POLYMAT and Polymer Science and Technology Department, Faculty of Chemistry, University of the Basque Country UPV/EHU, Paseo Manuel de Lardizabal 3, 20018 Donostia-San Sebastián, Spain

${ }^{\#}$ Flinders Institute for Nanoscale Science and Technology, Flinders University, Sturt Road, Bedford Park, Adelaide, SA 5042, Australia

${ }^{\nabla}$ Laboratoire de Chimie des Polymères Organiques (LCPO), University of Bordeaux, UMR 5629, B8 Allee Geoffroy Saint Hilaire, 33615 Pessac Cedex, France

ODresden Integrated Center for Applied Physics and Photonic Materials (IAPP) and Institute for Applied Physics, Technische Universität Dresden, Nöthnitzer Straße 61, 01187 Dresden, Germany

Cornell High Energy Synchrotron Source (CHESS), Ithaca, New York 14850, United States

IIInstitute for Materials Research (IMO-IMOMEC), Hasselt University, Wetenschapspark 1, 3590 Diepenbeek, Belgium

${ }^{\&}$ Ikerbasque, Basque Foundation for Science, E-48011 Bilbao, Spain

\section{Supporting Information}

ABSTRACT: Organic solar cells are thought to suffer from poor thermal stability of the active layer nanostructure, a common belief that is based on the extensive work that has been carried out on fullerene-based systems. We show that a widely studied non-fullerene acceptor, the indacenodithienothiophene-based acceptor ITIC, crystallizes in a profoundly different way as compared to fullerenes. Although fullerenes are frozen below the glass-transition temperature $T_{\mathrm{g}}$ of the photovoltaic blend, ITIC can undergo a glass-crystal transition considerably below its high $T_{\mathrm{g}}$ of $\sim 180^{\circ} \mathrm{C}$. Nanoscopic crystallites of a low-temperature polymorph are able to form through a diffusion-limited crystallization process. The resulting fine-grained nanostructure does not evolve further with time and hence is characterized by a high degree of thermal stability. Instead, above $T_{\mathrm{g}}$, the low temperature polymorph melts, and micrometer-sized crystals of a high-

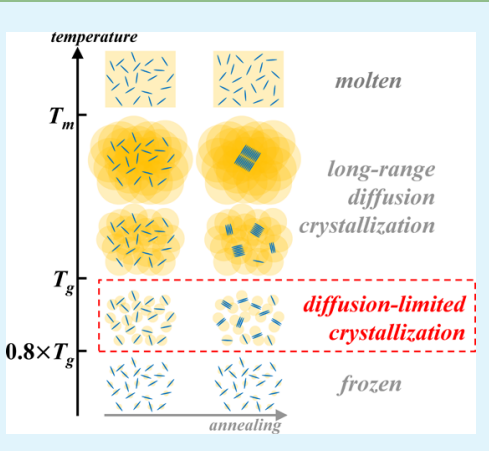
temperature polymorph develop, enabled by more rapid diffusion and hence long-range mass transport. This leads to the same detrimental decrease in photovoltaic performance that is known to occur also in the case of fullerene-based blends. Besides explaining the superior thermal stability of non-fullerene blends at relatively high temperatures, our work introduces a new rationale for the design of bulk heterojunctions that is not based on the selection of high- $T_{\mathrm{g}}$ materials per se but diffusion-limited crystallization. The planar structure of ITIC and potentially other non-fullerene acceptors readily facilitates the desired glass-crystal transition, which constitutes a significant advantage over fullerenes, and may pave the way for truly stable organic solar cells.

KEYWORDS: organic solar cell, thermally stable photovoltaics, glass-transition temperature, diffusion-limited crystallization, non-fullerene acceptor

\section{INTRODUCTION}

The low carbon footprint and short energy payback time projected for organic solar cells hold promise for both smallscale energy harvesting to power wearable electronics and gridscale electricity generation. To mature into a truly viable
Received: March 13, 2019

Accepted: May 23, 2019

Published: June 7, 2019 

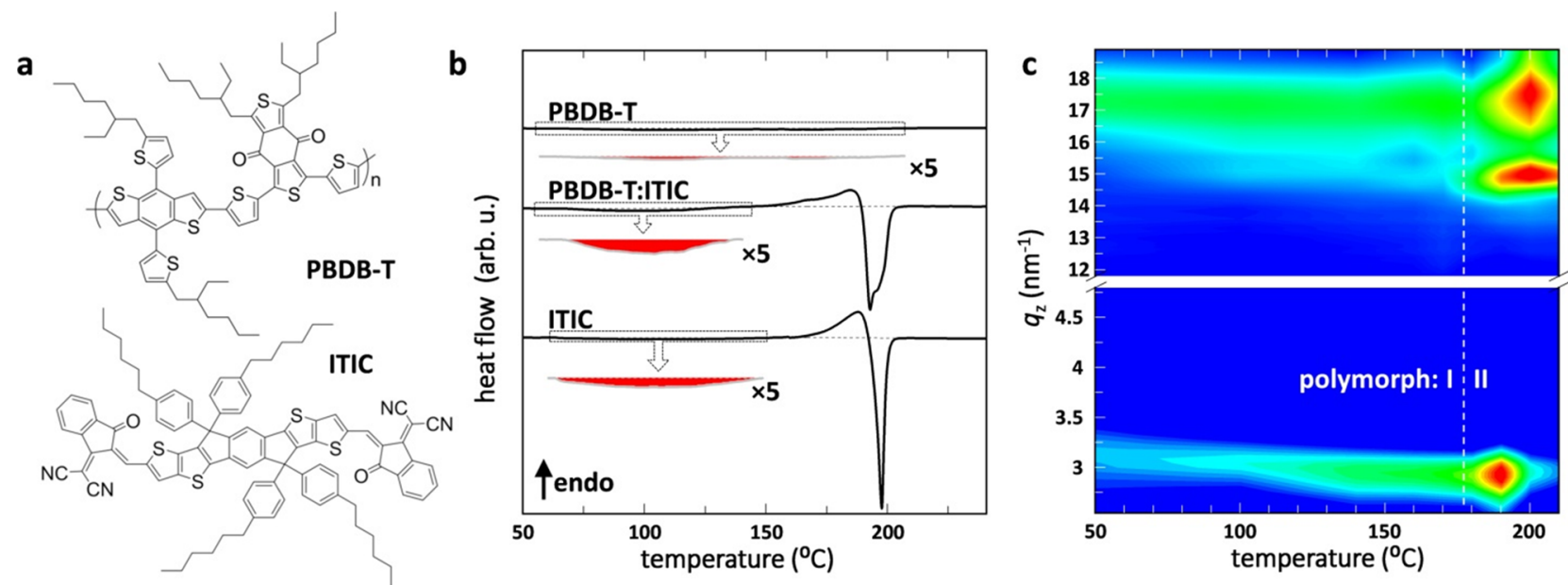

Figure 1. (a) Chemical structures of ITIC and PBDB-T; (b) first heating DSC thermograms of 1:1 ITIC:PBDB-T and the neat materials, solution cast from chlorobenzene (dashed baseline; exothermic recrystallization enlarged and colored red); (c) composite contour plot of out-of-plane integrated GIWAXS diffractograms of 1:1 ITIC:PBDB-T annealed for $10 \mathrm{~min}$ at various temperatures.

technology, it is paramount that organic solar cells exhibit, besides a high efficiency and low manufacturing cost, excellent long-term stability. ${ }^{1-3}$ Degradation of an organic solar cell can occur through photochemical processes, ${ }^{4-6}$ initiated by exposure to oxygen $^{7-9}$ and/or UV irradiation, ${ }^{4-6,10-12}$ which can be mitigated through appropriate encapsulation ${ }^{13,14}$ and the use of UV filters. ${ }^{15,16}$ Additionally, the nanostructure of the active layer is prone to evolve, in particular, upon heating during both fabrication and operation. ${ }^{17-21}$ Because the active layer nanostructure of organic photovoltaic blends must be carefully optimized to achieve high device efficiency, ${ }^{22}$ any change in the precise distribution of the donor and acceptor material(s) inevitably leads to a deterioration of the solar cell performance.

Much of the current understanding of processes that limit the thermal stability originates from the extensive work that has been carried out on blends based on fullerene acceptors, which have dominated the field of organic solar cells for a long time. Fullerenes such as phenyl- $\mathrm{C}_{61}$-butyric acid methyl ester $\left(\mathrm{PC}_{61} \mathrm{BM}\right)$ can only crystallize above the glass-transition temperature $T_{\mathrm{g}}$ (of the fullerene:polymer blend) where they suffer from a very low nucleation rate. ${ }^{23}$ Therefore, fullerenes tend to form micrometer-sized crystals that disrupt the active layer and hence deteriorate its photovoltaic performance. $^{17,18,20,23-25}$ Crystallization of fullerenes can be tamed by preventing the crystallization process altogether, which can be achieved by selecting donor polymers with a high $T_{g}{ }^{20,25-28}$ the use of fullerene alloys ${ }^{29-35}$ or dimers, ${ }^{36,37}$ and by crosslinking. ${ }^{38-41}$ Alternatively, crystallization can be controlled by enhancing the density of nuclei through the addition of a nucleating agent such as unsubstituted $\mathrm{C}_{60} \cdot{ }^{42,43}$ It is, however, not evident whether knowledge gained from fullerene-based photovoltaics can be applied to other material systems such as those based on alternative acceptors.

Currently, non-fullerene acceptors receive considerable attention because they now routinely lead to new record efficiencies of organic solar cells, reaching up to $15.7 \%$ in the case of single junction devices. ${ }^{44-50}$ Furthermore, there is a growing emphasis on the design of acceptors that show potential for a more cost-effective synthesis than that of fullerenes, absorb more strongly and display better chemical and thermal stability. Devices comprising materials such as the widely studied indacenodithienothiophene-based acceptor ITIC (see Figure 1a for chemical structure) now rival or even surpass the thermal stability of fullerene-based blends. ${ }^{44,51,52}$ For instance, blends of ITIC and the benzodithiophene-benzodithiophenedione-based donor copolymer PBDB- $\mathrm{T}^{53}$ (see Figure 1a for chemical structure) feature an unaltered solar cell performance at $100{ }^{\circ} \mathrm{C}$ for an extended period of time. ${ }^{44}$ Despite the highly promising thermal stability of blends comprising non-fullerene acceptors, there is a lack of studies that explore the underlying thermodynamic and kinetic processes that underpin their thermal evolution.

We, therefore, set out to study the crystallization behavior of the non-fullerene acceptor ITIC and its impact on the thermal stability of its blends with PBDB-T. We observe that, in contrast to fullerene-based blends, the acceptor is able to crystallize at temperatures considerably below its $T_{\mathrm{g}}$. This glass-crystal transition is known in the context of amorphous drugs, which are stored in a glassy state and must not crystallize to preserve their superior solubility and bioavailability. $^{26,54,55}$ Gratifyingly, we find that diffusion-limited crystallization below the $T_{\mathrm{g}}$ offers unique advantages for organic photovoltaic blends because it leads to the growth of nanometer-sized acceptor crystals and hence a highly metastable nanostructure that is characterized by excellent thermal stability.

\section{RESULTS AND DISCUSSION}

We started our investigation with thermal analysis of ITIC:PBDB-T blends using differential scanning calorimetry (DSC) at a scan rate of $10{ }^{\circ} \mathrm{C} \mathrm{min}^{-1}$. We purified the acceptor material immediately prior to our experiments because proton nuclear magnetic resonance $\left({ }^{1} \mathrm{H}\right.$ NMR) showed that ITIC gradually degrades during storage in air (Figure S1, Supporting Information). The first heating thermogram of the polymer cast from chlorobenzene is featureless apart from a very shallow exotherm (Figure 1b). In contrast, for ITIC, we observe, in addition to a shallow exotherm around $100{ }^{\circ} \mathrm{C}$, a distinct endotherm with a peak at $180{ }^{\circ} \mathrm{C}$ immediately followed by a sharp exotherm starting at $190^{\circ} \mathrm{C}$. We conclude that the acceptor is initially semicrystalline and above $190^{\circ} \mathrm{C}$, goes through a melting and recrystallization step, likely due to 

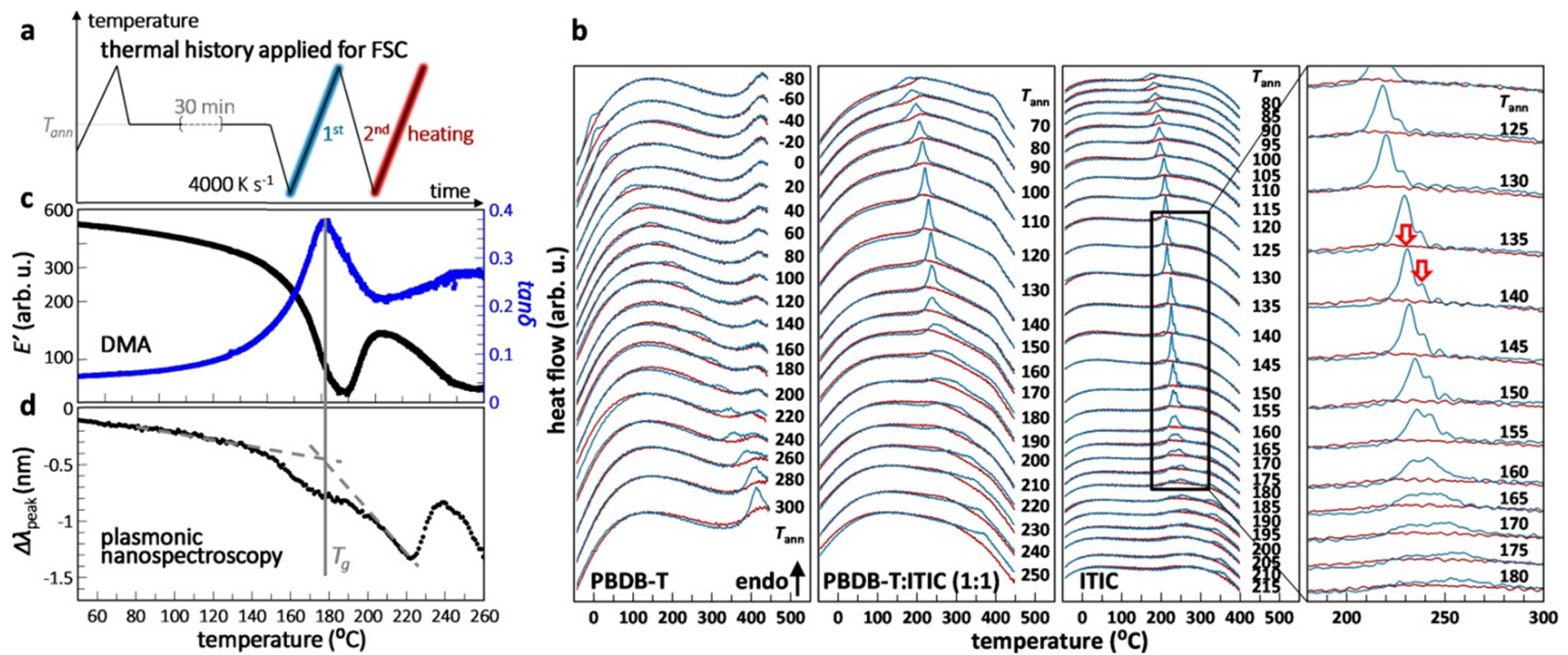

Figure 2. (a) Protocol used for FSC measurements where $T_{\text {ann }}$ is the annealing temperature; (b) first and second heating FSC thermograms of PBDB-T, 1:1 ITIC:PBDB-T, and ITIC after annealing at $T_{\text {ann }}$ (blue) and quenching from $450{ }^{\circ} \mathrm{C}$ at $4000 \mathrm{~K} \mathrm{~s}^{-1}$ (red); (c) DMA thermogram of 1:1 ITIC:PBDB-T showing the storage modulus $E^{\prime}$ and loss tangent $(\tan \delta)$, recorded after a pre-run to $160^{\circ} \mathrm{C}$; (d) plasmonic nanospectroscopy of $1: 1$ ITIC:PBDB-T showing the relative shift of the localized surface plasmon resonance (LSPR) peak $\Delta \lambda_{\text {peak}}$.

a polymorph change. The first heating DSC thermograms of the solution cast blend material (1:1 weight ratio) reveal the same features that are present for neat ITIC and a more pronounced broad exotherm around $100{ }^{\circ} \mathrm{C}$. The exotherm around $100{ }^{\circ} \mathrm{C}$ and endotherm at $180{ }^{\circ} \mathrm{C}$ display an almost identical enthalpy of about $8.7 \mathrm{~J} \mathrm{~g}^{-1}$ (calculated based on the weight of ITIC, see Figure S2 of the Supporting Information) in the case of both the neat acceptor and the blend, which suggests that, after solidification from the solution, the acceptor material is mostly amorphous. Initially, at least some acceptor molecules are likely to reside in the polymerrich matrix. Hence, the aggregation of the polymer upon heating, indicated by the shallow DSC exotherm and increase in diffraction intensity (Figure S3, Supporting Information), assists the phase separation and crystallization of ITIC. To confirm that ITIC underwent a polymorph change, we monitored the nanostructure of the $1: 1$ blend material annealed at various temperatures with grazing incidence wide-angle X-ray scattering (GIWAXS) (Figure 1c). Above $100{ }^{\circ} \mathrm{C}$, we observe the appearance of a diffraction around 15.5 $\mathrm{nm}^{-1}$ (see Figure S4 of Supporting Information for line cut at $160{ }^{\circ} \mathrm{C}$ ), which is a characteristic of neat ITIC solidified from chlorobenzene (Figure S3, Supporting Information). Above $180^{\circ} \mathrm{C}$, we observe an abrupt change in the scattering pattern, characterized by the appearance of a high intensity diffraction at $15 \mathrm{~nm}^{-1}$, consistent with neat ITIC annealed in this temperature range. We conclude that ITIC undergoes a change in the polymorph at $180{ }^{\circ} \mathrm{C}$, and we label the low- and hightemperature polymorphs as polymorphs I and II, respectively (cf. Figure 1c).

To explore the thermotropic behavior of ITIC in more detail, we employed fast scanning calorimetry (FSC). We performed physical aging experiments at various temperatures to determine the upper limit of the $T_{\mathrm{g} .}{ }^{56}$ Physical aging can only take place below the glass-transition temperature as long as at least some molecular reorganization is permitted at the experimental timescale. An endothermic overshoot in a calorimetric heating scan subsequent to extended aging is a sign that the glassy-state system is able to spontaneously evolve toward a more equilibrated thermodynamic state reducing its enthalpy and volume below the $T_{\mathrm{g}}$. In our set of experiments, we subjected the materials to rapid heating at $4000 \mathrm{~K} \mathrm{~s}^{-1}$, both after annealing (aging) at different temperatures $T_{\text {ann }}$ for 30 min and after quenching from $450{ }^{\circ} \mathrm{C}$; the latter step allowed us to obtain reference scans of the material that did not have time to crystallize or relax (see Figure 2a for thermal history of FSC scans). For both, quenched ITIC and a quenched 1:1 ITIC:PBDB-T blend, an endothermic overshoot can only be detected in the case of aging temperatures below $200{ }^{\circ} \mathrm{C}$, suggesting an upper limit for a $T_{\mathrm{g}}$ of ITIC of about $200{ }^{\circ} \mathrm{C}$ (when vitrified at $4000{ }^{\circ} \mathrm{C} \mathrm{s}^{-1}$ ). Hence, we assign the step function in the FSC thermograms with a midpoint around 180 ${ }^{\circ} \mathrm{C}$ to the glass transition of the acceptor material (Figure $2 \mathrm{~b}$ ).

Because blending with the polymer does not appear to alter the $T_{\mathrm{g}}$ of the acceptor, we argue that the blend has undergone phase separation and that ITIC-rich domains are present. Indeed, atomic force microscopy (AFM, cf. Figure S5, Supporting Information) shows features on the order of several tens of nanometers in the case of both as-cast and annealed blends. To verify that ITIC has a $T_{\mathrm{g}}$ of $\sim 180^{\circ} \mathrm{C}$, we employed dynamic mechanical analysis (DMA) and plasmonic nanospectroscopy (Figure 2c,d), as described elsewhere. ${ }^{57,58}$ The DMA thermogram of a 1:1 ITIC:PBDB-T blend features a significant drop in storage modulus above $140{ }^{\circ} \mathrm{C}$ and the loss tangent $(\tan \delta)$ peaks at $179{ }^{\circ} \mathrm{C}$, which confirms the high $T_{\mathrm{g}}$ deduced by FSC. Plasmonic nanospectroscopy reveals a $T_{\mathrm{g}}$ in the same temperature range, extrapolated from the change in the rate by which the peak of the plasmonic resonance shifts with temperature.

The endotherm observed for neat ITIC and the 1:1 ITIC:PBDB-T blend in DSC scans closely overlaps in temperature with the enthalpy relaxation found in FSC measurements. Careful examination of the FSC thermograms subsequent to annealing at $T_{\mathrm{ann}}<T_{\mathrm{g}}$ reveals two distinguishable endothermic transitions (Figure $2 \mathrm{~b}$; rightmost panel). The first transition dominates the signal for ITIC annealed at 
temperatures up to $120{ }^{\circ} \mathrm{C}$. Instead, for $T_{\text {ann }}>120{ }^{\circ} \mathrm{C}$, a second signal located at a slightly higher temperature increases in prominence. We assign the first endothermic transition to the enthalpy recovery associated with the glass transition as its intensity decreases for annealing close to the $T_{\mathrm{g}}$. The second transition at a slightly higher temperature was not observed until the material was annealed above $0.8 \times T_{\mathrm{g}}\left(\sim 90^{\circ} \mathrm{C}\right)$ and peaked only below the $T_{\mathrm{g}}$. This transition could possibly be the trace of melting of polymorph I crystals formed in the temperature range $0.8 \times T_{\mathrm{g}}<T_{\mathrm{ann}}<T_{\mathrm{g}}$. In contrast, for $T_{\mathrm{ann}}>$ $T_{\mathrm{g}}$, melting occurs around $350{ }^{\circ} \mathrm{C}$ (Figure 2b) suggesting another polymorph (e.g., polymorph II).

We propose that ITIC, in contrast to fullerene acceptors, is able to crystallize into polymorph I far below its $T_{\mathrm{g}}$ of $\sim 180^{\circ} \mathrm{C}$ through diffusion-limited crystallization (Figure 3 ). This type

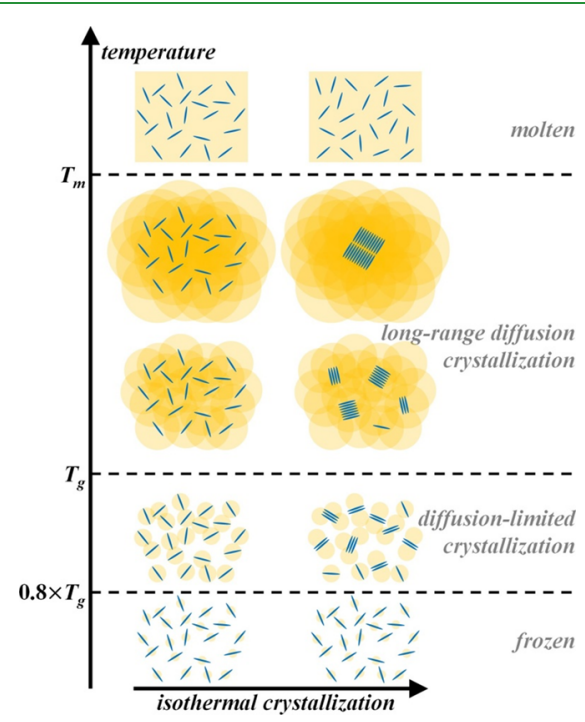

Figure 3. Schematic illustrating isothermal crystallization of ITIC molecules (blue) within a matrix at various temperatures, with concentric yellow circles illustrating the accessible volume. Below 0.8 $\times T_{\mathrm{g}}$, molecules are frozen and fully localized. In the regime, $0.8 \times T_{\mathrm{g}}$ $<T_{\text {ann }}<T_{\mathrm{g}}$ local diffusion allows crystallization into polymorph I nanocrystals. Above $T_{\mathrm{g}}$ but below the melting temperature $T_{\mathrm{m}}$, longrange mass transport leads to the formation of larger polymorph II crystals.

of crystallization behavior is common for many pharmaceutical compounds such as paracetamol, indomethacin, celecoxib, nifedipine, and ibuprofen, ${ }^{59-63}$ which can crystallize considerably below their glass-transition temperature. ${ }^{62,64}$ At temperatures below $T_{\mathrm{g}}$, the acceptor can only diffuse locally, which allows ITIC molecules to reorganize and join a crystal growth front that is present in their close vicinity. Instead, above $T_{\mathrm{g}}$, the acceptor solidifies through more rapid and long-range diffusion into polymorph II. The occurrence of distinct polymorphs above and below the $T_{\mathrm{g}}$ and a phase transformation involving the melting of one phase and crystallization of another polymorph have also been reported for ibuprofen. ${ }^{63}$

In a further set of experiments, we investigated how the diffusion-limited crystallization into polymorph I below $T_{\mathrm{g}}$, and the transformation into polymorph II above $T_{\mathrm{g}}$ affects the distribution of the acceptor material. To this end, we studied thin films with polarized optical microscopy and scanning electron microscopy (SEM). Optical microscopy reveals that crystallites start to appear upon annealing for $10 \mathrm{~min}$ at $T_{\mathrm{ann}}>$
$100{ }^{\circ} \mathrm{C}$ in initially featureless as-cast films (Figure 4). Raman microscopy confirmed that the observed crystallites are
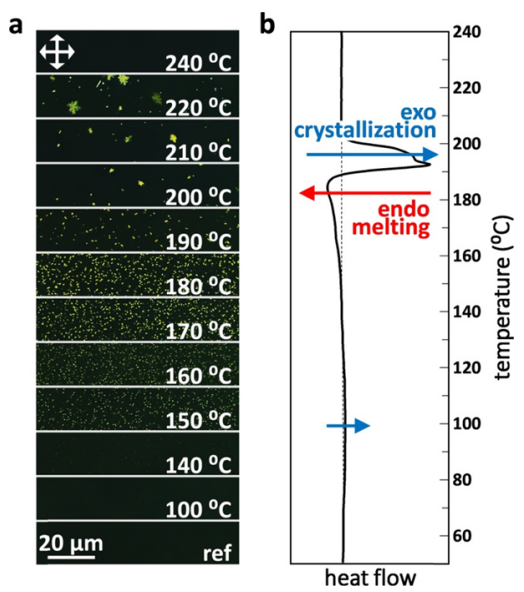

Figure 4. (a) Polarized optical microscopy images of 1:1 ITIC:PBDB$\mathrm{T}$ thin films deposited on $\mathrm{Si}$ wafers annealed at 100 to $240{ }^{\circ} \mathrm{C}$ for 10 min compared to (b) DSC heating thermogram of 1:1 ITIC:PBDB-T solution cast from chlorobenzene.

composed of ITIC as evidenced by a pronounced signal of the CN stretching vibration (Figure S6, Supporting Information). We observe two different regimes below and above $T_{\mathrm{g}}$ of $\sim 180{ }^{\circ} \mathrm{C}$, which are characterized by a markedly different size and shape of crystallites. SEM images indicate that polymorph I crystallites have a sheet-like structure with a thickness around $100 \mathrm{~nm}$ and a lateral extent of up to $500 \mathrm{~nm}$. Their growth is accompanied by a gradual increase in quenching of the acceptor photoluminescence above $100{ }^{\circ} \mathrm{C}$ (Figure S8, Supporting Information). Instead, crystallization of polymorph II above $T_{\mathrm{g}}$ leads to large, micrometer-sized spherulites that can be easily discerned in polarized optical micrographs. In addition, we observe a strong increase in ITIC photoluminescence (Figure S8, Supporting Information). We argue that diffusion-limited crystallization into polymorph I below $T_{g}$, in combination with a high tendency of the planar ITIC acceptor to aggregate, likely caused by $\pi-\pi$ interactions, leads to nanoscopic crystallites with a high aspect ratio. Crystallization is also assisted by the strong densification of amorphous ITIC annealed/aged below the $T_{\mathrm{g}}$, suggested by the notable enthalpy recovery found in the FSC aging experiments (see Figure $2 \mathrm{~b}$ ). In contrast, polymorph II crystals form above $T_{\mathrm{g}}$ where long-range mass transport increases the crystal growth rate, resulting in much larger crystallites that likely deteriorate the photovoltaic performance of ITIC:PBDB$\mathrm{T}$ blends.

To judge the impact of the two annealing regimes on the nucleation rate, we counted the number of crystallites by analyzing both optical microscopy and SEM images (Figures 5 and 6). For polymorph I, we deduce a nucleation density as high as $1.1 \times 10^{8} \mathrm{~cm}^{-2}$ by optical microscopy and $8 \times 10^{7}$ $\mathrm{cm}^{-2}$ by SEM at $160^{\circ} \mathrm{C}$ (Figure 5), which is one to two orders of magnitude higher than values reported for $\mathrm{PC}_{61} \mathrm{BM}^{23,43}$ unless nucleated with $\mathrm{C}_{60}{ }^{43}$ Instead, for polymorph II, we estimate from optical micrographs a much lower nucleation density of only $1 \times 10^{5} \mathrm{~cm}^{-2}$ at $220{ }^{\circ} \mathrm{C}$. We also investigated the influence of the processing additive 1,8-diiodooctane (DIO) on the populations of polymorph I and II crystallites because DIO is known to improve the photovoltaic perform- 

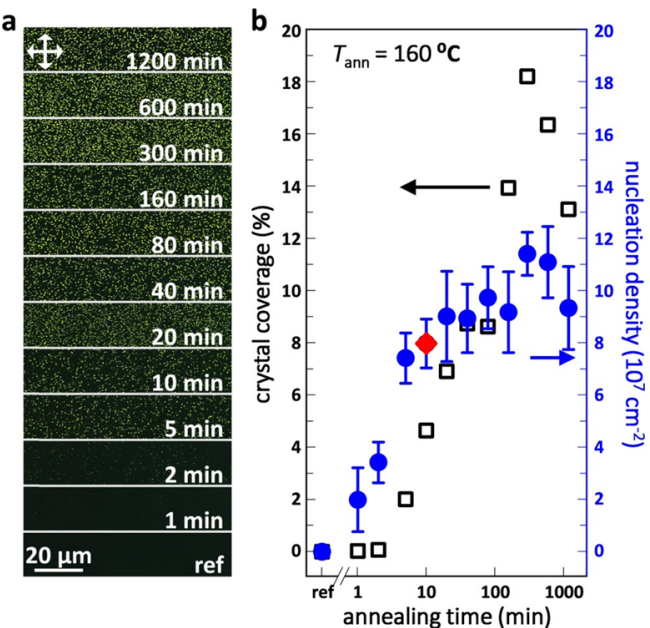

Figure 5. (a) Polarized optical microscopy images of 1:1 ITIC:PBDB$\mathrm{T}$ thin films deposited on silicon wafers annealed for different duration at $160{ }^{\circ} \mathrm{C}$; (b) crystal area coverage (black open squares) and nucleation density (filled symbols, see Figure S10 of the Supporting Information for the method used to estimate the nucleation density) estimated from optical microscopy images (blue circles, error bar representing the standard deviation) and SEM images (red diamond). The reference is the unannealed film. a

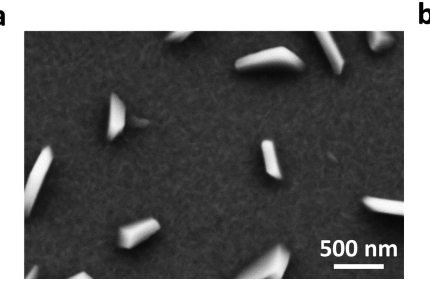

b

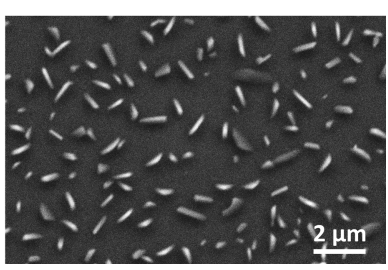

Figure 6. (a, b) Two SEM images of ITIC polymorph I crystals, grown at $160^{\circ} \mathrm{C}$ in a $1: 1$ ITIC:PBDB-T thin film deposited on silicon wafers.

ance of ITIC:PBDB-T blends. ${ }^{44,65,66}$ From SEM (Figure S9, Supporting Information), we find an even higher nucleation density of $4 \times 10^{8} \mathrm{~cm}^{-2}$ for polymorph I crystallites grown at $160{ }^{\circ} \mathrm{C}$ for $10 \mathrm{~min}$ in films prepared by spin coating using a solution containing 0.5 vol \% DIO. In addition, the use of DIO further reduces the lateral extent of ITIC crystallites to now less than $50 \mathrm{~nm}$ in sheet thickness.

To study the impact of the two polymorphs on the photovoltaic performance of ITIC:PBDB-T blends, we constructed a series of organic solar cells consisting of a layer stack of glass/ITO/PEDOT:PSS/active layer/LiF/Al. Initially, we studied devices that differed in the stoichiometry of the active layer blend. Blends with a 1:1 ratio of ITIC and PBDB-T by weight showed the highest short-circuit current density $\left(J_{\text {sc }}\right)$ of $\sim 14 \mathrm{~mA} \mathrm{~cm}{ }^{-2}$, accompanied by an open-circuit voltage $\left(V_{\mathrm{oc}}\right)$ of $\sim 0.9 \mathrm{~V}$ and fill factor $(\mathrm{FF})$ of $\sim 0.5$, giving rise to a power conversion efficiency (PCE) of about $7 \%$ (Figure S12, Supporting Information). We therefore chose to study the thermal stability of 1:1 ITIC:PBDB-T blends in more detail. To this end, we annealed active layers for $10 \mathrm{~min}$ at various temperatures prior to evaporation of the top electrode. The formation of polymorph I crystallites upon annealing at $T_{\text {ann }}>$ $100{ }^{\circ} \mathrm{C}$ is accompanied by an increase in the fill factor leading to a slight improvement in PCE to $7.5 \%$ (Figure 7). Instead, annealing at temperatures close to or above the $T_{\mathrm{g}}$ of $\sim 180{ }^{\circ} \mathrm{C}$ of the acceptor resulted in a gradual deterioration of all photovoltaic parameters. The observed reduction in $V_{\text {oc }}$ from 0.9 to $0.85 \mathrm{~V}$ is consistent with the appearance of a broad subgap absorption band, visible in sensitive external quantum efficiency (sEQE) measurements (Figure S11, Supporting Information), indicating a change in the energy of the charge transfer state $E_{\mathrm{CT}} \cdot{ }^{67}$ We argue that the emergence of coarser polymorph II crystals disrupts the nanostructure of the studied ITIC:PBDB-T blends, resulting in a reduced $J_{\text {sc }}$ and FF. The impact of polymorph II crystals on the PCE is, therefore, comparable to the commonly observed reduction in the efficiency of $\mathrm{PC}_{61} \mathrm{BM}$-based devices upon growth of micrometer-sized fullerene crystals.

In a final set of experiments, we focused on the long-term stability at elevated temperature. We chose to carry out our experiments at $160{ }^{\circ} \mathrm{C}$, which lies only slightly below the $T_{\mathrm{g}}$ of $\sim 180^{\circ} \mathrm{C}$, where gradual structural changes over a long period of time, for example, a conversion from polymorph I to II, are likely. Note that Zhao et al. have previously reported excellent thermal stability of ITIC:PBDB-T-based solar cells annealed for 10 days at $100{ }^{\circ} \mathrm{C} .{ }^{44}$ During the first few minutes of annealing, a slight drop in $V_{\mathrm{oc}}$ is compensated by an increase in FF, overall leading to a stable PCE for the first $10 \mathrm{~min}$ at 160 ${ }^{\circ} \mathrm{C}$ (Figure 7 and Figure S13 of the Supporting Information). At longer times, the PCE gradually deteriorates due to a loss in $J_{\text {sc }}$, which we assign to a transformation from polymorph I to II, corroborated by optical microscopy and GIWAXS (Figure S14, Supporting Information). Optical microscopy and GIWAXS suggest that the thin film nanostructure is almost unchanged for a much longer duration than $10 \mathrm{~min}$ when annealing at 160 ${ }^{\circ} \mathrm{C}$. We argue that solar cell devices are more sensitive to minor changes in the nanostructure. Regardless, ITIC:PBDB-T-based solar cells offer a sufficiently long processing window of $10 \mathrm{~min}$ at $160{ }^{\circ} \mathrm{C}$ for rapid solvent removal and lamination, which is needed for high-speed manufacturing and encapsulation. Coincidentally, $160{ }^{\circ} \mathrm{C}$ is also the highest continuous service temperature of one of the most heat-resistant types of substrate: poly(ethylene naphthalate) (PEN) films.

\section{CONCLUSIONS}

We have shown that the acceptor ITIC crystallizes in a different way as compared to fullerenes, which bestows blends of ITIC and the polymer PBDB-T with a superior thermal stability. ITIC is able to crystallize at temperatures considerably below its high $T_{\mathrm{g}}$ of $\sim 180{ }^{\circ} \mathrm{C}$ through a glasscrystal transition. This diffusion-limited process leads to a very high nucleation density and hence the formation of a metastable blend nanostructure characterized by nanoscopic crystallites of a low-temperature ITIC polymorph. These nanoscopic polymorph I crystallites do not negatively affect the device performance. In addition, these crystallites do not evolve further with time as long as the temperature remains sufficiently below the $T_{g}$, and hence, the nanostructure displays a high degree of thermal stability. Instead, above $T_{\mathrm{g}}$, long-range diffusion and crystallization of a high-temperature ITIC polymorph result in micrometer-sized crystals, which, similar to micrometer-sized fullerene crystals, have a detrimental impact on the photovoltaic performance. We conclude that diffusion-limited crystallization of non-fullerene acceptors below $T_{\mathrm{g}}$ is a powerful tool to improve the reproducibility (see Figure S15 of the Supporting Information) and long-term stability of organic solar cells and represents a considerable advantage over fullerene acceptors. 

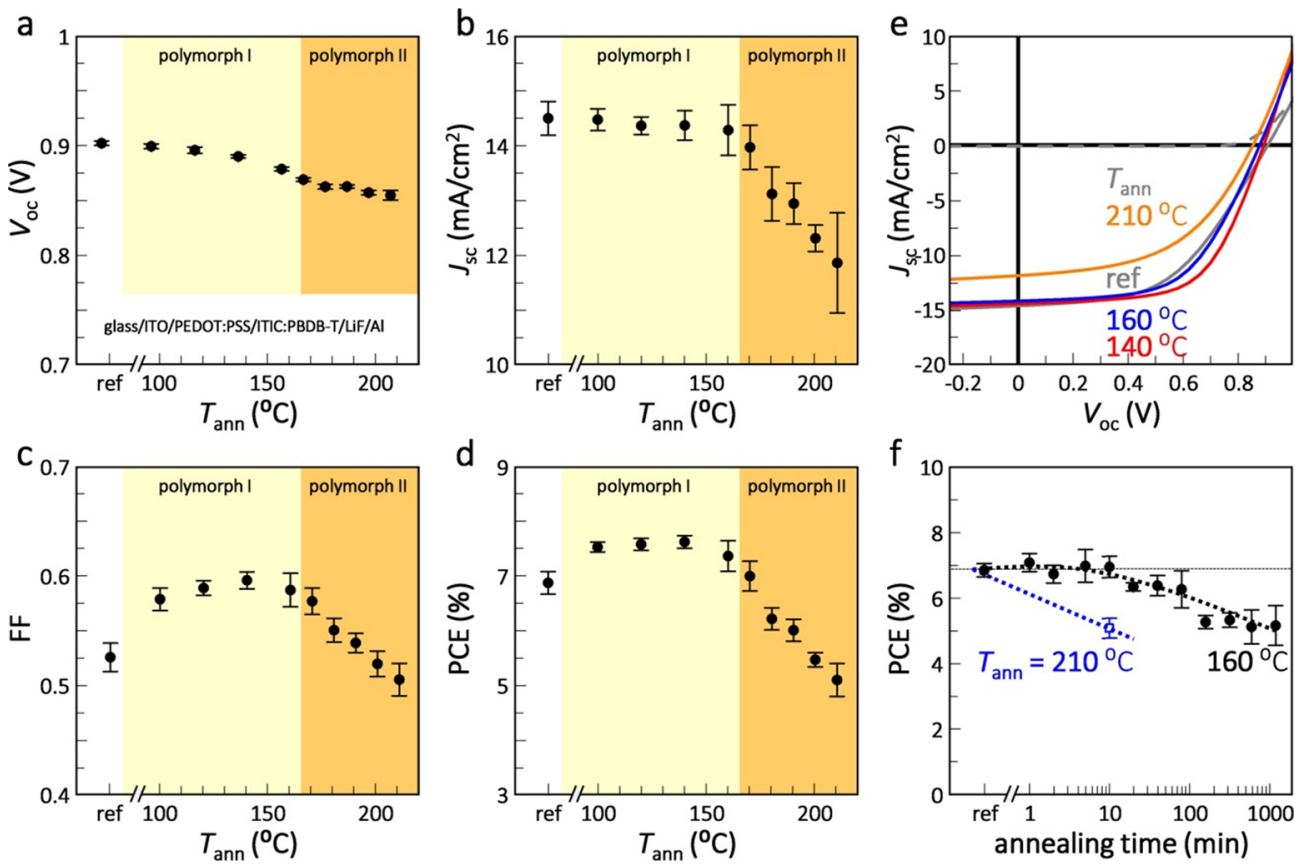

Figure 7. $(a-d)$ Device parameters (solid symbols representing the mean value of eight devices and the error bars representing the standard deviation) of 1:1 ITIC:PBDB-T solar cells with active layers annealed for $10 \mathrm{~min}$ at temperatures up to $210{ }^{\circ} \mathrm{C}$ : (a) open-circuit voltage $V_{\text {oc }}$ (the device architecture is described in the inset), (b) short-circuit current density $J_{s c}$ (c) fill factor FF, and (d) power-conversion efficiency PCE. (e) Typical $J-V$ characteristics of the reference (unannealed) device and devices annealed at various temperatures. The dark current (dashed gray line) of the reference device is also displayed. (f) PCE of ITIC:PBDB-T solar cells annealed for various time at $160{ }^{\circ} \mathrm{C}$ (black solid circles) or $210{ }^{\circ} \mathrm{C}$ (open square) (see Figure S13 of the Supporting Information for other device parameters).

\section{EXPERIMENTAL SECTION}

4.1. Materials and Purification. ITIC and PBDB-T were purchased from Solarmer Ltd. PBDB-T $\left(M_{\mathrm{n}}=17 \mathrm{~kg} \mathrm{~mol}^{-1}\right.$; PDI $=$ 3.7) was used as received. ${ }^{1} \mathrm{H}$ NMR spectra of ITIC were recorded with a $400 \mathrm{MHz}$ nuclear magnetic resonance spectrometer that indicated the presence of impurities in the as-received batch (Figure S1). Aside from the parent proton peaks of ITIC, we observe several additional peaks in the aromatic region of the ${ }^{1} \mathrm{H}$ NMR spectrum, suggesting the presence of one or more unknown impurities. We purified ITIC by flash column chromatography on silica gel with 2:3 dichloromethane:hexane as the eluent. After purification, a ${ }^{1} \mathrm{H}$ NMR spectrum was collected again that corresponded to the previously reported experimental data of ITIC. ${ }^{68}$

4.2. Differential Scanning Calorimetry (DSC). DSC was conducted at a heating/cooling rate of $10{ }^{\circ} \mathrm{C} \mathrm{min}^{-1}$ with a Mettler Toledo DSC2 equipped with a high-sensitivity sensor (HSS9+). Mettler $20 \mu \mathrm{L} \mathrm{Al} \mathrm{crucible} \mathrm{light} \mathrm{sample} \mathrm{pans} \mathrm{were} \mathrm{used.} \mathrm{Around} 6 \mathrm{mg}$ of material was used for each measurement and collected from films cast at room temperature from chlorobenzene solutions $\left(20 \mathrm{~g} \mathrm{~L}^{-1}\right)$.

4.3. Fast Scanning Calorimetry (FSC). FSC was conducted with a Mettler Toledo Flash DSC 1 equipped with an intracooler and nitrogen purge. Thin films were deposited directly on the backside of the FSC chip from $20 \mathrm{~g} \mathrm{~L}^{-1}$ chlorobenzene solutions. The measurement protocol is shown in Figure 2a.

4.4. Dynamic Mechanical Analysis (DMA). Measurements were performed under nitrogen flow $\left(60 \mathrm{~mL} \mathrm{~min}^{-1}\right)$ in a strain-controlled mode (maximum strain $<0.1 \%$ ) at a frequency of $1 \mathrm{~Hz}$ and a heating rate of $3{ }^{\circ} \mathrm{C} \mathrm{min}{ }^{-1}$ using a TA Instruments Q800 DMA. The materials were embedded in a glass fiber mesh (E-glass supplied by Hexcel) by casting from a $20 \mathrm{~g} \mathrm{~L}^{-1}$ chlorobenzene solution followed by drying under vacuum at room temperature overnight. The glass mesh was cut into strips at a $45^{\circ}$ angle with respect to the fiber elongation to avoid any continuous fibers crossing the length of the sample and contributing to the DMA response (see ref 20 for details).

4.5. Plasmonic Nanospectroscopy. Measurements were done under argon at a heating rate of $5{ }^{\circ} \mathrm{C} \mathrm{min}^{-1}$ using sensors comprised of $170 \times 20 \mathrm{~nm}$ (diameter $\times$ height $)$ Au nanodisk arrays, encapsulated with a conformal $10 \mathrm{~nm} \mathrm{SiO}$ film, as described previously. ${ }^{58}$ Materials were deposited onto the sensors by spin coating from a $20 \mathrm{~g} \mathrm{~L}^{-1}$ chlorobenzene solution. The sensors were illuminated using a fibercoupled halogen lamp (AvaLight-HAL-S, Avantes) while the extinction spectra were continuously recorded by a fiber-coupled fixed grating spectrometer (AvaSpec-1024, Avantes). The shift of the localized surface plasmon resonance (LSPR) peak $\Delta \lambda_{\text {peak }}$ was obtained by fitting the measured extinction spectra to a $20^{\circ}$ polynomial.

4.6. Polarized Optical Microscopy. Images were recorded in a reflecting mode with a Zeiss Axio Scope Al equipped with a pair of crossed polarizers. Samples were spin coated from a $20 \mathrm{~g} \mathrm{~L}^{-1}$ chlorobenzene solution on silicon wafers. The microscopies are taken with a Zeiss EC Epiplan $100 \times$ length with a numerical aperture of 0.85 , a condenser with a numerical aperture of 0.9 , and an AxioCam MRc 5 camera. The estimated resolution is $380 \mathrm{~nm}$ at a wavelength of $550 \mathrm{~nm}$.

4.7. Atomic Force Microscopy (AFM). Atomic force microscopy was performed with a Bruker Dimension ICON atomic force microscope in the PeakForce KPFM mode using a PFTUNA tip ( $k$, $\sim 0.4 \mathrm{~N} \mathrm{~m}^{-1}$ ) on samples spin coated on silicon wafers.

4.8. Scanning Electron Microscopy (SEM). SEM was conducted on areas without top electrodes on the solar cell samples with a Leo Ultra 55 SEM at $3 \mathrm{kV}$ using an InLens detector at a working distance of $9.7 \mathrm{~mm}$.

4.9. Grazing Incidence Wide-Angle $X$-ray Scattering (GIWAXS). Measurements were performed at the D-line, Cornell High Energy Synchrotron Source (CHESS) at Cornell University. The X-ray beam with a wavelength of $1.162 \AA$ and size of about 0.5 $\mathrm{mm}$ was directed onto the samples at an incident angle of $0.15^{\circ}$. Measurements were done on either the areas without top electrodes on the solar cell samples discussed in this work (Figure 1 and Figure S14) or films deposited on silicon wafers (Figure S3). An optical microscope, located vertically above the sample, was used to monitor the beam and sample location so that only areas free of Al top 
electrodes were irradiated. A Pilatus $200 \mathrm{~K}$ detector located $177.2 \mathrm{~mm}$ from the sample was used with an exposure time of $3 \mathrm{~s}$.

4.10. Photoluminescence Spectroscopy. Spectra were recorded on thin films as prepared for the solar cells with an Andor spectrometer (Shamrock sr-303i-B, coupled to a Newton EMCCD Si array detector cooled to $-60{ }^{\circ} \mathrm{C}$ ). A $670 \mathrm{~nm}$ laser was used as a pumping light source.

4.11. Organic Solar Cell Devices. Solar cell devices were fabricated on glass substrates with indium tin oxide (ITO) as a conductive coating. Poly(3,4-ethylenedioxythiophene):poly(styrenesulfonate) (PEDOT:PSS) was spin coated onto the substrates and dried at $150{ }^{\circ} \mathrm{C}$ for $10 \mathrm{~min}$. Then, ITIC:PBDB-T with a $1: 1$ weight ratio (unless otherwise specified) was spin coated under nitrogen at $2500 \mathrm{rpm}$ for $60 \mathrm{~s}$ from a $20 \mathrm{~g} \mathrm{~L}^{-1}$ chlorobenzene solution containing 0.5 vol \% 1,8-diiodooctane (DIO). Annealing was done under nitrogen followed by deposition of $\mathrm{LiF}$ and the $\mathrm{Al}$ top electrode by thermal evaporation through a mask, which defined an active area of $7 \mathrm{~mm}^{2}$. Devices were measured in air without encapsulation. $J-V$ curves (measured in the forward direction with a scan step of $0.04 \mathrm{~V}$ ) were collected using a Keithley 2400 source meter under AM1.5 illumination provided by a solar simulator (LSH-7320 ABA LED solar simulator) with an intensity equivalent to $1000 \mathrm{~W} \mathrm{~m}^{-2}$ after a spectral mismatch correction.

4.12. Sensitive External Quantum Efficiency (sEQE). Measurements were conducted on solar cell devices, which were encapsulated by gluing glass slides on the top of the active area. The light of a quartz halogen lamp $(50 \mathrm{~W})$ was chopped at $141 \mathrm{~Hz}$ and coupled into a monochromator (Newport Cornerstone $2601 / 4$ $\mathrm{m})$. The resulting monochromatic light is focused onto the organic solar cell; its short-circuit current is fed to a current-voltage preamplifier and then analyzed with a lock-in amplifier (Signal Recovery 7280 DSP). The time constant of the lock-in amplifier was chosen to be $1 \mathrm{~s}$, and the amplification of the preamplifier was increased to resolve low photocurrents. The sEQE is determined by dividing the photocurrent of the organic solar cell by the flux of incoming photons, which was obtained with a calibrated silicon $(\mathrm{Si})$ and indium-gallium-arsenide (InGaAs) photodiode.

\section{ASSOCIATED CONTENT}

\section{S Supporting Information}

The Supporting Information is available free of charge on the ACS Publications website at DOI: 10.1021/acsami.9b04554.

NMR; first heating DSC thermograms; out-of-plane integration of GIWAXS images; qualitative maps of AFM images; Raman spectroscopy; normalized UV-vis absorption; SEM images; polarized optical microscopy; normalized sensitive $\mathrm{EQE}_{\mathrm{PV}}$ spectra; device parameters; composite contour plot; a plot summarizing PCE of devices (PDF)

\section{AUTHOR INFORMATION}

\section{Corresponding Authors}

*E-mail: liyangy@chalmers.se (L.Y.).

*E-mail: christian.muller@chalmers.se (C.M.).

\section{ORCID}

Liyang Yu: 0000-0002-1203-2996

Ferry A. A. Nugroho: 0000-0001-5571-0454

Anirudh Sharma: 0000-0003-4841-0108

Anna I. Hofmann: 0000-0002-4480-6028

Johannes Benduhn: 0000-0001-5683-9495

Detlef-M. Smilgies: 0000-0001-9351-581X

Koen Vandewal: 0000-0001-5471-383X

Mats R. Andersson: 0000-0002-7928-8216

Jaime Martín: 0000-0002-9669-7273

Feng Gao: 0000-0002-2582-1740
Christian Müller: 0000-0001-7859-7909

\section{Notes}

The authors declare no competing financial interest.

\section{ACKNOWLEDGMENTS}

We acknowledge financial support from the Knut and Alice Wallenberg Foundation through the project "Mastering Morphology for Solution-borne Electronics", the Swedish Research Council (grant agreement no. 2016-06146), and the Swedish Foundation for Strategic Research (grant agreement no. RMA15-0052). We thank the Cornell High Energy Synchrotron Source (CHESS), supported by the NSF under award DMR-1332208, for providing time for GIWAXS measurements. J.B. and K.V. acknowledge funding from the German Federal Ministry for Education and Research (BMBF) through the InnoProfile project "Organische p-i-n Bauelemente 2.2" (03IPT602X).

\section{REFERENCES}

(1) Jørgensen, M.; Norrman, K.; Gevorgyan, S. A.; Tromholt, T.; Andreasen, B.; Krebs, F. C. Stability of Polymer Solar Cells. Adv. Mater. 2012, 24, 580-612.

(2) Krebs, F. C.; Gevorgyan, S. A.; Alstrup, J. A Roll-to-Roll Process to Flexible Polymer Solar Cells: Model Studies, Manufacture and Operational Stability Studies. J. Mater. Chem. 2009, 19, 5442-5451.

(3) Grossiord, N.; Kroon, J. M.; Andriessen, R.; Blom, P. W. M. Degradation Mechanisms in Organic Photovoltaic Devices. Org. Electron. 2012, 13, 432-456.

(4) Rivaton, A.; Tournebize, A.; Gaume, J.; Bussière, P.-O.; Gardette, J.-L.; Therias, S. Photostability of Organic Materials Used in Polymer Solar Cells. Polym. Int. 2014, 63, 1335-1345.

(5) Anselmo, A. S.; Dzwilewski, A.; Svensson, K.; Moons, E. Photodegradation of the Electronic Structure of PCBM and C60 Films in Air. Chem. Phys. Lett. 2016, 652, 220-224.

(6) Hintz, H.; Egelhaaf, H.-J.; Lüer, L.; Hauch, J.; Peisert, H.; Chassé, T. Photodegradation of P3HT-A Systematic Study of Environmental Factors. Chem. Mater. 2011, 23, 145-154.

(7) Tapponnier, A.; Biaggio, I.; Günter, P. Ultrapure C60 FieldEffect Transistors and the Effects of Oxygen Exposure. Appl. Phys. Lett. 2005, 86, 112114.

(8) lüer, L.; Egelhaaf, H.-J.; Oelkrug, D.; Cerullo, G.; Lanzani, G.; Huisman, B.-H.; de Leeuw, D. M. Oxygen-Induced Quenching of Photoexcited States in Polythiophene Films. Org. Electron. 2004, 5, $83-89$.

(9) Egelhaaf, H.-J.; Lüer, L.; Oelkrug, D.; Winter, G.; Haisch, P.; Hanack, M. Influence of Oxygen Doping on the Photoconductivity of $\pi$-Conjugated Molecules. Synth. Met. 1997, 84, 897-898.

(10) Lessmann, R.; Hong, Z.; Scholz, S.; Maennig, B.; Riede, M. K.; Leo, K. Aging of Flat Heterojunction Zinc Phthalocyanine/Fullerene C60 Organic Solar Cells. Org. Electron. 2010, 11, 539-543.

(11) Eklund, P. C.; Rao, A. M.; Zhou, P.; Wang, Y.; Holden, J. M. Photochemical Transformation of C60 and C70 Films. Thin Solid Films 1995, 257, 185-203.

(12) Hamed, A.; Sun, Y. Y.; Tao, Y. K.; Meng, R. L.; Hor, P. H. Effects of Oxygen and Illumination on the in Situ Conductivity of $\mathrm{C}$ 60 Thin Films. Phys. Rev. B 1993, 47, 10873-10880.

(13) Peters, C. H.; Sachs-Quintana, I. T.; Kastrop, J. P.; Beaupré, S.; Leclerc, M.; McGehee, M. D. High Efficiency Polymer Solar Cells with Long Operating Lifetimes. Adv. Energy Mater. 2011, 1, 491-494.

(14) Giannouli, M.; Drakonakis, V. M.; Savva, A.; Eleftheriou, P.; Florides, G.; Choulis, S. A. Methods for Improving the Lifetime Performance of Organic Photovoltaics with Low-Costing Encapsulation. ChemPhysChem 2015, 16, 1134-1154.

(15) Córcoles, L.; Abad, J.; Padilla, J.; Urbina, A. Wavelength Influence on the Photodegradation of P3HT:PCBM Organic Solar Cells. Sol. Energy Mater. Sol. Cells 2015, 141, 423-428. 
(16) Fernandes, R. V.; Bristow, N.; Stoichkov, V.; Anizelli, H. S.; Duarte, J. L.; Laureto, E.; Kettle, J. Development of Multidye UV Filters for OPVs Using Luminescent Materials. J. Phys. D: Appl. Phys. 2017, 50, No. 025103.

(17) Zhao, J.; Swinnen, A.; van Assche, G.; Manca, J.; Vanderzande, D.; van Mele, B. Phase Diagram of P3HT/PCBM Blends and Its Implication for the Stability of Morphology. J. Phys. Chem. B 2009, 113, 1587-1591.

(18) Bertho, S.; Janssen, G.; Cleij, T. J.; Conings, B.; Moons, W.; Gadisa, A.; D’Haen, J.; Goovaerts, E.; Lutsen, L.; Manca, J.; Vanderzande, D. Effect of Temperature on the Morphological and Photovoltaic Stability of Bulk Heterojunction Polymer:Fullerene Solar Cells. Sol. Energy Mater. Sol. Cells 2008, 92, 753-760.

(19) Yang, X.; Loos, J. Toward High-Performance Polymer Solar Cells: The Importance of Morphology Control. Macromolecules 2007, 40, 1353-1362.

(20) Müller, C.; Bergqvist, J.; Vandewal, K.; Tvingstedt, K.; Anselmo, A. S.; Magnusson, R.; Alonso, M. I.; Moons, E.; Arwin, H.; Campoy-Quiles, M.; Inganäs, O. Phase Behaviour of LiquidCrystalline Polymer/Fullerene Organic photovoltaic Blends: Thermal Stability and Miscibility. J. Mater. Chem. 2011, 21, 10676-10684.

(21) Yang, X.; Van Duren, J. K. J.; Janssen, R. A. J.; Michels, M. A. J.; Loos, J. Morphology and Thermal Stability of the Active Layer in Poly(p-Phenylenevinylene)/Methanofullerene Plastic Photovoltaic Devices. Macromolecules 2004, 37, 2151-2158.

(22) Reyes-Reyes, M.; Kim, K.; Carroll, D. L. High-Efficiency Photovoltaic Devices Based on Annealed Poly(3-Hexylthiophene) and 1-(3-Methoxycarbonyl)-Propyl-1- Phenyl-(6,6)C61 Blends. Appl. Phys. Lett. 2005, 87, No. 083506.

(23) Lindqvist, C.; Sanz-Velasco, A.; Wang, E.; Bäcke, O.; Gustafsson, S.; Olsson, E.; Andersson, M. R.; Müller, C. Nucleation-Limited Fullerene Crystallisation in a Polymer-Fullerene Bulk-Heterojunction Blend. J. Mater. Chem. A 2013, 1, 7174-7180.

(24) Hindson, J. C.; Ulgut, B.; Friend, R. H.; Greenham, N. C.; Norder, B.; Kotlewski, A.; Dingemans, T. J. All-Aromatic Liquid Crystal Triphenylamine-Based Poly(Azomethine)s as Hole Transport Materials for Opto-Electronic Applications. J. Mater. Chem. 2010, 20, 937-944.

(25) Müller, C. On the Glass Transition of Polymer Semiconductors and Its Impact on Polymer Solar Cell Stability. Chem. Mater. 2015, 27, 2740-2754.

(26) Laitinen, R.; Löbmann, K.; Strachan, C. J.; Grohganz, H.; Rades, T. Emerging Trends in the Stabilization of Amorphous Drugs. Int. J. Pharm. 2013, 453, 65-79.

(27) Bergqvist, J.; Lindqvist, C.; Bäcke, O.; Ma, Z.; Tang, Z.; Tress, W.; Gustafsson, S.; Wang, E.; Olsson, E.; Andersson, M. R.; Inganäs, O.; Müller, C. Sub-Glass Transition Annealing Enhances Polymer Solar Cell Performance. J. Mater. Chem. A 2014, 2, 6146-6152.

(28) Vandenbergh, J.; Conings, B.; Bertho, S.; Kesters, J.; Spoltore, D.; Esiner, S.; Zhao, J.; Van Assche, G.; Wienk, M. M.; Maes, W.; Lutsen, L.; Van Mele, B.; Janssen, R. A. J.; Manca, J.; Vanderzande, D. J. M. Thermal Stability of Poly[2-Methoxy-5-(2'-Phenylethoxy)-1,4Phenylenevinylene] (MPE-PPV):Fullerene Bulk Heterojunction Solar Cells. Macromolecules 2011, 44, 8470-8478.

(29) Lindqvist, C.; Bergqvist, J.; Bäcke, O.; Gustafsson, S.; Wang, E.; Olsson, E.; Inganäs, O.; Andersson, M. R.; Müller, C. Fullerene Mixtures Enhance the Thermal Stability of a Non-Crystalline Polymer Solar Cell Blend. Appl. Phys. Lett. 2014, 104, 153301.

(30) de Zerio Mendaza, A. D.; Melianas, A.; Rossbauer, S.; Bäcke, O.; Nordstierna, L.; Erhart, P.; Olsson, E.; Anthopoulos, T. D.; Inganäs, O.; Müller, C. High-Entropy Mixtures of Pristine Fullerenes for Solution-Processed Transistors and Solar Cells. Adv. Mater. 2015, $27,7325-7331$.

(31) de Zerio Mendaza, A. D.; Melianas, A.; Nugroho, F. A. A.; Bäcke, O.; Olsson, E.; Langhammer, C.; Inganäs, O.; Müller, C. A Fullerene Alloy Based Photovoltaic Blend with a Glass Transition Temperature above $200{ }^{\circ} \mathrm{C}$. J. Mater. Chem. A 2017, 5, 4156-4162.

(32) Cheng, P.; Yan, C.; Wu, Y.; Wang, J.; Qin, M.; An, Q.; Cao, J.; Huo, L.; Zhang, F.; Ding, L.; Sun, Y.; Ma, W.; Zhan, X. Alloy
Acceptor: Superior Alternative to PCBM toward Efficient and Stable Organic Solar Cells. Adv. Mater. 2016, 28, 8021-8028.

(33) An, Q.; Zhang, F.; Zhang, J.; Tang, W.; Deng, Z.; Hu, B. Versatile Ternary Organic Solar Cells: A Critical Review. Energy Environ. Sci. 2016, 9, 281-322.

(34) Ameri, T.; Khoram, P.; Min, J.; Brabec, C. J. Organic Ternary Solar Cells: A Review. Adv. Mater. 2013, 25, 4245-4266.

(35) de Zerio, A. D.; Müller, C. Glass Forming Acceptor Alloys for Highly Efficient and Thermally Stable Ternary Organic Solar Cells. Adv. Energy Mater. 2018, 8, 1702741.

(36) Li, Z.; Wong, H. C.; Huang, Z.; Zhong, H.; Tan, C. H.; Tsoi, W. C.; Kim, J. S.; Durrant, J. R.; Cabral, J. T. Performance Enhancement of Fullerene-Based Solar Cells by Light Processing. Nat. Commun. 2013, 4, 2227.

(37) Piersimoni, F.; Degutis, G.; Bertho, S.; Vandewal, K.; Spoltore, D.; Vangerven, T.; Drijkoningen, J.; van Bael, M. K.; Hardy, A.; D'Haen, J.; Maes, W.; Vanderzande, D.; Nesladek, M.; Manca, J. Influence of Fullerene Photodimerization on the PCBM Crystallization in Polymer: Fullerene Bulk Heterojunctions under Thermal Stress. J. Polym. Sci., Part B: Polym. Phys. 2013, 51, 1209-1214.

(38) Diacon, A.; Derue, L.; Lecourtier, C.; Dautel, O.; Wantz, G.; Hudhomme, P. Cross-Linkable Azido C 60 -Fullerene Derivatives for Efficient Thermal Stabilization of Polymer Bulk-Heterojunction Solar Cells. J. Mater. Chem. C 2014, 2, 7163-1767.

(39) Miyanishi, S.; Tajima, K.; Hashimoto, K. Morphological Stabilization of Polymer Photovoltaic Cells by Using Cross-Linkable Poly(3-(5-Hexenyl)Thiophene). Macromolecules 2009, 42, 16101618.

(40) Kim, B. J.; Miyamoto, Y.; Ma, B.; Fréchet, J. M. J. Photocrosslinkable Polythiophenes for Efficient, Thermally Stable, Organic Photovoltaics. Adv. Funct. Mater. 2009, 19, 2273-2281.

(41) Drees, M.; Hoppe, H.; Winder, C.; Neugebauer, H.; Sariciftci, N. S.; Schwinger, W.; Schäffler, F.; Topf, C.; Scharber, M. C.; Zhu, Z.; Gaudiana, R. Stabilization of the Nanomorphology of PolymerFullerene "Bulk Heterojunction" Blends Using a Novel Polymerizable Fullerene Derivative. J. Mater. Chem. 2005, 15, 5158-1563.

(42) Richards, J. J.; Rice, A. H.; Nelson, R. D.; Kim, F. S.; Jenekhe, S. A.; Luscombe, C. K.; Pozzo, D. C. Modification of PCBM Crystallization via Incorporation of C60in Polymer/Fullerene Solar Cells. Adv. Funct. Mater. 2013, 23, 514-522.

(43) Lindqvist, C.; Bergqvist, J.; Feng, C.-C.; Gustafsson, S.; Bäcke, O.; Treat, N. D.; Bounioux, C.; Henriksson, P.; Kroon, R.; Wang, E.; Sanz-Velasco, A.; Kristiansen, P. M.; Stingelin, N.; Olsson, E.; Inganäs, O.; Andersson, M. R.; Mülller, C. Fullerene Nucleating Agents: A Route towards Thermally Stable Photovoltaic Blends. Adv. Energy Mater. 2014, 4, 1301437.

(44) Zhao, W.; Qian, D.; Zhang, S.; Li, S.; Inganäs, O.; Gao, F.; Hou, J. Fullerene-Free Polymer Solar Cells with over 11\% Efficiency and Excellent Thermal Stability. Adv. Mater. 2016, 28, 4734-4739.

(45) Yuan, J.; Zhang, Y.; Zhou, L.; Zhang, G.; Yip, H.-L.; Lau, T.-K.; Lu, X.; Zhu, C.; Peng, H.; Johnson, P. A.; Leclerc, M.; Cao, Y.; Ulanski, J.; Li, Y.; Zou, Y. Single-Junction Organic Solar Cell with over 15\% Efficiency Using Fused-Ring Acceptor with ElectronDeficient Core. Joule 2019, 3, 1140-1151.

(46) Yan, C.; Barlow, S.; Wang, Z.; Yan, H.; Jen, A. K.-Y.; Marder, S. R.; Zhan, X. Non-Fullerene Acceptors for Organic Solar Cells. Nat. Rev. Mater. 2018, 3, 18003.

(47) Zhang, G.; Zhao, J.; Chow, P. C. Y.; Jiang, K.; Zhang, J.; Zhu, Z.; Zhang, J.; Huang, F.; Yan, H. Nonfullerene Acceptor Molecules for Bulk Heterojunction Organic Solar Cells. Chem. Rev. 2018, 118, 3447-3507.

(48) Wadsworth, A.; Moser, M.; Marks, A.; Little, M. S.; Gasparini, N.; Brabec, C. J.; Baran, D.; McCulloch, I. Critical Review of the Molecular Design Progress in Non-Fullerene Electron Acceptors towards Commercially Viable Organic Solar Cells. Chem. Soc. Rev. 2019, 48, 1596-1625.

(49) Hou, J.; Inganäs, O.; Friend, R. H.; Gao, F. Organic Solar Cells Based on Non-Fullerene Acceptors. Nat. Mater. 2018, 17, 119-128. 
(50) Fei, Z.; Eisner, F. D.; Jiao, X.; Azzouzi, M.; Röhr, J. A.; Han, Y.; Shahid, M.; Chesman, A. S. R.; Easton, C. D.; McNeill, C. R.; Anthopoulos, T. D.; Nelson, J.; Heeney, M. An Alkylated Indacenodithieno[3,2-b]Thiophene-Based Nonfullerene Acceptor with High Crystallinity Exhibiting Single Junction Solar Cell Efficiencies Greater than 13\% with Low Voltage Losses. Adv. Mater. 2018, 30, 1705209 .

(51) Li, S.; Zhan, L.; Liu, F.; Ren, J.; Shi, M.; Li, C.-Z.; Russell, T. P.; Chen, H. An Unfused-Core-Based Nonfullerene Acceptor Enables High-Efficiency Organic Solar Cells with Excellent Morphological Stability at High Temperatures. Adv. Mater. 2018, 30, 1705208.

(52) Lee, H. K. H.; Durrant, J. R.; Li, Z.; Tsoi, W. C. Stability Study of Thermal Cycling on Organic Solar Cells. J. Mater. Res. 2018, 33, 1902-1908.

(53) Qian, D.; Ye, L.; Zhang, M.; Liang, Y.; Li, L.; Huang, Y.; Guo, X.; Zhang, S.; Tan, Z.; Hou, J. Design, Application, and Morphology Study of a New Photovoltaic Polymer with Strong Aggregation in Solution State. Macromolecules 2012, 45, 9611-9617.

(54) Developing Solid Oral Dosage Forms, Qiu, Y., Chen, Y., Zhang, G. G., Yu, L., Mantri, R. V.; Academic Press, 2009.

(55) Sun, Y.; Zhu, L.; Wu, T.; Cai, T.; Gunn, E. M.; Yu, L. Stability of Amorphous Pharmaceutical Solids: Crystal Growth Mechanisms and Effect of Polymer Additives. AAPS J. 2012, 14, 380-388.

(56) Martín, J.; Stingelin, N.; Cangialosi, D. Direct Calorimetric Observation of the Rigid Amorphous Fraction in a Semiconducting Polymer. J. Phys. Chem. Lett. 2018, 9, 990-995.

(57) Sharma, A.; Pan, X.; Campbell, J. A.; Andersson, M. R.; Lewis, D. A. Unravelling the Thermomechanical Properties of Bulk Heterojunction Blends in Polymer Solar Cells. Macromolecules 2017, 50, 3347-3354.

(58) Nugroho, F. A. A.; Diaz de Zerio Mendaza, A.; Lindqvist, C.; Antosiewicz, T. J.; Müller, C.; Langhammer, C. Plasmonic Nanospectroscopy for Thermal Analysis of Organic Semiconductor Thin Films. Anal. Chem. 2017, 89, 2575-2582.

(59) Grzybowska, K.; Paluch, M.; Grzybowski, A.; Wojnarowska, Z.; Hawelek, L.; Kolodziejczyk, K.; Ngai, K. L. Molecular Dynamics and Physical Stability of Amorphous Anti-Inflammatory Drug: Celecoxib. J. Phys. Chem. B 2010, 114, 12792-12801.

(60) Kissi, E. O.; Grohganz, H.; Löbmann, K.; Ruggiero, M. T.; Zeitler, J. A.; Rades, T. Glass-Transition Temperature of the $\beta$ Relaxation as the Major Predictive Parameter for Recrystallization of Neat Amorphous Drugs. J. Phys. Chem. B 2018, 122, 2803-2808.

(61) Sibik, J.; Löbmann, K.; Rades, T.; Zeitler, J. A. Predicting Crystallization of Amorphous Drugs with Terahertz Spectroscopy. Mol. Pharmaceutics 2015, 12, 3062-3068.

(62) Kaminska, E.; Tarnacka, M.; Kaminski, K.; Ngai, K. L.; Paluch, M. Changes in Dynamics of the Glass-Forming Pharmaceutical Nifedipine in Binary Mixtures with Octaacetylmaltose. Eur. J. Pharm. Biopharm. 2015, 97, 185-191.

(63) Dudognon, E.; Danède, F.; Descamps, M.; Correia, N. T. Evidence for a New Crystalline Phase of Racemic Ibuprofen. Pharm. Res. 2008, 25, 2853-2858.

(64) Nath, R.; el Goresy, T.; Geil, B.; Zimmermann, H.; Böhmer, R. Relaxation in the Glass Former Acetylsalicylic Acid Studied by Deuteron Magnetic Resonance and Dielectric Spectroscopy. Phys. Rev. E 2006, 74, No. 021506.

(65) Zhao, W.; Zhang, S.; Hou, J. Realizing 11.3\% Efficiency in Fullerene-Free Polymer Solar Cells by Device Optimization. Sci. China Chem. 2016, 59, 1574-1582.

(66) Lin, Y.; Jin, Y.; Dong, S.; Zheng, W.; Yang, J.; Liu, A.; Liu, F.; Jiang, Y.; Russell, T. P.; Zhang, F.; Huang, F.; Hou, L. Printed Nonfullerene Organic Solar Cells with the Highest Efficiency of 9.5\%. Adv. Energy Mater. 2018, 8, 1701942.

(67) Vandewal, K.; Tvingstedt, K.; Gadisa, A.; Inganäs, O.; Manca, J. V. Relating the Open-Circuit Voltage to Interface Molecular Properties of Donor:Acceptor Bulk Heterojunction Solar Cells. Phys. Rev. B 2010, 81, 125204.
(68) Lin, Y.; Wang, J.; Zhang, Z. G.; Bai, H.; Li, Y.; Zhu, D.; Zhan, $X$. An Electron Acceptor Challenging Fullerenes for Efficient Polymer Solar Cells. Adv. Mater. 2015, 27, 1170-1174. 